\title{
Utilizing Evaluation Evidence to Enhance Professional Practice ${ }^{1}$
}

\author{
HELEN SIMONS \\ University of Southampton, UK
}

The purpose of this article is to re-examine the current use of what is to count as evaluation evidence to inform professional practice. The provision of evaluation evidence to inform decision making has long been an aspiration, albeit with varying degrees of success. However the need to re-examine the utility of this endeavour has arisen in the contemporary culture of evidence-based policy and practice. The main argument of the article is that the politically favoured approach to this task fails to recognize the holistic nature of professional practice and disregards the complexity of professional decision making and action. The article offers a critique of the dominant model of evidence-based in relation to the nature of professional practice and argues that it is time to reassert the value of qualitative methodologies to maximize the utilization of evaluation evidence by professional practitioners.

KEYWORDS: evaluation; evidence-based practice; narrative; professional practice; qualitative methods

\section{Introduction}

Three decades have passed since quantitative methodology was found to be inadequate as the sole provider of knowledge for action in the sphere of public services. It has a place, but without the contextualization and understanding of personal experience that qualitative methods provide, it is sorely lacking in explanatory or educative power. Despite these rather obvious limitations, we are now faced with a politically driven restoration of the numbers game, under the banner of evidence-based policy and practice (EBPP) with randomized experiments its predominant feature (House, 2003). Government seeks a closer relationship with the research and evaluation community and a more prescriptive role in determining the 'what' and the 'how' of policy-related inquiry. It is the 'how' - the methodology - that is problematic. Simplicity and certainty are what governments seek. Complexity and uncertainty are what we habitually deliver. Standardization of treatment, preferably based on a 'scientific' endorsement, gives them confidence. The government want to know what works, and we 
have to tell them that nothing works everywhere, and that their best bet is to fully understand why this is so. At a political level the drive for more efficient management of investments in the public services results in favouring a model of investigation that promises conclusive answers about what works. Is this just a passing fad not worthy of our attention? I think not; we have made that mistake too often, and the result is a school performance system that is grossly unjust and a health service at the mercy of political priorities. Nor should we ignore the fact that this solution to reforming public services is now enshrined in the educational legislature of the USA (Slavin, 2002). Contexts differ of course and we have yet in the UK to see the full import of such a model in practice. However there is sufficient evidence in the discussion that follows to indicate that the controversy in the dominant discourse of evidence-based practice (EBP) centres to a large degree on the faith accorded to experimental-control comparisons on standardsbased measures as a basis for policy intervention.

The purpose of this article is to challenge the simplistic demands of government agencies by illustrating and defending the kind of inquiry that, for the past three decades, has elaborated the complexity of professional decision making and fostered understanding of social, personal and professional life. If we view the generation of knowledge from an understanding of the nature of professional practice, the kinds of knowledge that are useful for informing policy and practice differ from the dominant model in the current discourse. The basic argument is that if we wish to generate policy to inform practice and persuade professionals to review that practice, we need to give greater value than is currently the case to evidence that incorporates the reality of their practice and the anatomy of their decision making. In making this case, I am not saying that other kinds of systematic evidence or experimental intervention studies are not useful for certain purposes and contexts. It is a question of appropriateness of method for purpose and function - in this case, of improving practice.

The article is divided into four sections. First is a short discussion of professional practice as a focus for determining the nature of appropriate evidence for informing practice. Second is a brief review of the early aspirations of evaluation as a field of inquiry to indicate that evidence-based inquiry is not a new concept what is new is the contemporary policy context. Thirdly the origins for this reemergence of EBPP are examined and a critique of the dominant model offered in relation to professional practice. Fourthly, a re-justification is presented for forms of evidence that value 'lived experience', primarily through an exploration of the clinical narrative. The article concludes by arguing that the inclusion of personal narratives and other forms of lived experience is an important way forward to ensure greater interest in and utilization of evidence by those who deliver our public services and those who receive them.

\section{The Nature of Professional Practice}

Several authors have made the point that the concept of $\mathrm{EBP}^{2}$ allows different conceptions of evidence (Humphries, 2003), different methods - quantitative and qualitative (Davies, 1999; Sebba, 1999) - and responsiveness to context (Sackett 


\section{Evaluation 10(4)}

et al., 1996; Greenhalgh and Worrall, 1997). Yet many have also noted, that in the current political climate of 'what works', there is a 'dominant model' of EBP and an emphasis on 'scientific rationality' (e.g. Sanderson, 2003; Humphries, 2003; Tilley, 2001; Oliver and Conole, 2003).

The dominant model these authors refer to is the randomized controlled trial (RCT), what Eraut (2003) refers to, in the case of healthcare interventions in medicine, as the 'gold standard' of medical research paramount in the Cochrane Database of Systematic Reviews, and Tilley (2001: 84), in the context of evaluation, as the gold standard for evaluation studies. In RCTs subjects are allocated blindly and randomly to experimental and control groups. Both are measured before and after treatment given to the experimental group and any difference is attributable to the intervention. (For further elaboration of this approach and its role in social interventions see Fitz-Gibbon, 2003; Oakley, 1998; and Slavin, 2002.)

In this conception of EBP, practice seems to be perceived as a 'doing', a craftlike implementation of techniques. Improving practice is a technical-rational process of adoption of evidence from intervention studies of what has been demonstrated to work 'best' across a large sample of the population. Context is ignored and the agency of the person and their contribution to the knowledge base are not a critical factor (Humphries, 2003).

A different conception of practice, the one that is the prime focus of this article, sees practice as an educational, moral, practical activity in which the agency of the person and the socio-political context are integral to the generation and use of evidence to inform practice. The making of moral judgements about how to act should take into account 'scientific evidence' (knowledge) where it is relevant and available, but this should not supplant professional judgement and practical knowledge in practice contexts (Schwandt, 2000). Eraut (2003) makes a similar point when he says that practice-based evidence, the term he adopts to refer to evidence derived from professional practices, is always used in making decisions about a client but that this can be informed by 'other scientific evidence' or 'research based evidence'. Professional practice, he says, both generates and uses evidence. While these are sometimes linked by agency, they can be mutually interactive or separated by time, space and lack of interaction but whichever, the distinction between the context of evidence generation and the context of evidence use remains important (Eraut, 2003).

That professional practice is a moral ethical activity is also evident in the writings of Elliott (1990, 2001). In his critique of Hargreaves' ideas about the nature of EBP, for example, Elliott points out that Hargreaves' account of the sort of research evidence that can be used to inform pedagogical development confines itself to evidence of instrumental effectiveness (Elliott, 2001: 564). In Elliott's argument, educational research (and by extension evaluation in this context), if it is to inform educational practice, should prioritize the gathering of empirical evidence which can inform teachers' judgements about how their practices correspond with the procedural values and principles that define a worthwhile process of education (Elliott, 2001). The approach most likely to realize this aspiration, he says, is one in which teachers are actively involved in prioritizing educational aims in a given situation, in defining what is to count as 
relevant evidence of the extent to which they are being realized and in interpreting its practical significance for them (Elliott, 2001: 565). See also Humphries (2003) for a strong argument for the use of participatory approaches in evidencebased social work.

In summary, those who view practice as an educational, moral activity in which practitioners are directly involved in the process, will take a different view on the generation and diffusion of evaluation evidence from those who believe that practice can be informed through the technical adoption of evaluation results determined by other means. It is this difference in relation to the improvement of practice and what kinds of knowledge are likely to improve practice, I suggest, that lies at the heart of the debate over EBP. Though sometimes presented as a debate about methodologies, at a fundamental level it is a question of epistemology and who decides what kind of knowledge counts as evidence. Not all forms of EBP have the direct intention to improve practice. Those that aspire to inform policy have a more indirect relationship to practice. Nevertheless, long term, if policies are to be determined on the basis of evidence and effectively implemented, some awareness of the nature of professional practice as a practical moral activity is important to this end. Part of the argument of this article is to re-examine which kinds of evidence are more likely to contribute to the world of professional practice conceived as a moral activity.

\section{Where We Have Been}

\section{Evaluation Evidence for Decision Making}

Using evaluation evidence ${ }^{3}$ to inform policy and practice has been the sine qua non of evaluation practice since Cronbach (1963) and Stufflebeam et al. (1971) first defined evaluation as a process of providing information to make decisions about educational programmes. Later, of course, Cronbach and colleagues (Cronbach et al., 1980) redefined this definition to the aspiration of informing policy making or judgement in the long term, acknowledging that policy decisions are rarely, if ever, taken solely on the basis of evidence from specific evaluations.

Earlier, evaluators had broadened the scope of what counts as evidence (see Stake's [1967] countenance model for one example) and recognized the utility of qualitative, interpretivist approaches for representing experience in context (for an overview of the utility of these approaches see Greene [1994]). The inherent political nature of evaluation and the difficulty of generating and disseminating evaluation evidence in complex socio-political contexts, had also been acknowledged by, among others, MacDonald (1976), House (1980) and Weiss $(1975,1977)$. Aware of the need to be responsive (methodologically and politically) to different values and interests in a pluralistic society, many evaluators adopted a more modest and educative approach to the task aspiring 'not to produce authoritative truths but to clarify, to document, to raise new questions, and to create new perceptions' (Lindblom and Cohen, 1979; quoted in Cronbach et al., 1980: 53).

We have known this now for over 30 years and hopefully have embedded a more complex relationship between evidence and informing decision making 


\section{Evaluation 10(4)}

into evaluation practice. Hence my surprise, in one sense, that we are having to argue the ground all over again. More will be said in the next section about the reasons for the rise of 'evidence-based' in the contemporary culture. However first it is important to recall something of what we have learned in evaluation over the past 30 years. As the terrain is vast my observations are restricted to developments in qualitative evaluation with particular pertinence to professional practice. Not all evaluations have this aspiration. Of the many purposes of evaluation outlined by Chelimsky (1997), the one this article is primarily concerned with is evaluation for development, which may include evaluation for understanding and knowledge. It is less concerned with other purposes of evaluation such as efficiency, impact, performance management and accountability. While different methodologies may be adopted in the pursuit of evidence to enhance practice, those that are particularly appropriate include participatory/democratic, case study, narrative and responsive/stakeholder approaches.

\section{Practice-based Professions: Evolution of Alternative Evaluation Approaches}

In the early 1970s there was a major shift in educational evaluation away from experimental and objectives-focused, pre-post-test, research designs for informing complex decisions educators had to make, whether in national large-scale studies or local schools and classrooms (e.g. Norris, 1991; Simons, 1987; Greene, 1994). In the field of educational evaluation, the above models were found inadequate for capturing the complexity of innovations, the fluidity of their changing nature and the cultural diversity of contexts of implementation. A different kind of understanding was required, one that was situated in context, documented the uniqueness of the case and engaged those being evaluated in contributing significantly to the interpretation and analysis of the programme. Today case study and participatory democratic approaches in evaluation are widely accepted and legitimated in many professional fields that have educational intent and consequences (e.g. Stake, 1995; Simons, 1996; Shaw, 1999; Ryan and DeStefano, 2000; Guba and Lincoln, 1989).

Parallel with the development of case study evaluation was the growth of action research, sponsored by the work of Stenhouse (1975) and Elliott (1990), which focused on teachers experimenting in their own classrooms with how to improve teaching performance and enhance student learning. In both these movements qualitative methods were found to be insightful and useful in understanding the case or practice setting. The kind of knowledge generated by interview, observation, critical incidents, vignettes, cameos, narrative accounts (Eisner, 1985; Abma, 1999) and case studies (Stake, 1995; MacDonald and Walker, 1975) provided a rich description and analysis of experience from which many stakeholders could learn. Their appeal was directly to the person reading the case. Unlike large sample studies, the person was uniquely involved, whether the case was a person, an institution, a programme or, in the case of medicine, a health-related problem or disease.

In other disciplines in the social sciences (especially in psychology and sociology), at the same time there were parallel developments towards more 
context-sensitive, humanistic and personal ways of knowing and understanding. The same was the case in the practice professions of nursing, healthcare and social work (e.g. Dowell et al., 1995; Goldstein, 1991; Shaw and Gould, 2001) and medicine (Greenhalgh and Worrall, 1997; Davies, 1999).

The author is not advancing the case here that these qualitative methods replaced previous methods in currency for evaluation of public programmes. Other methods and designs continued to be used singly or in combination for certain purposes. However they did provide an alternative and gained legitimacy for understanding the complexity of social and educational programmes and informing stakeholders of the reasons why these succeeded or failed for which groups in what contexts and circumstances.

This brief review of developments in the uptake of qualitative evaluation, which pays attention to people's experience, culture and context in different professional settings, has been cited to remind us that the current focus on EBP threatens a return to what many professionals rejected years ago as inappropriate for improving practice. It is important to keep the reasons for these developments in the foreground as we encounter the current EBP debate.

\section{Contemporary Movement of Evidence-based Practice}

\section{Origin and Focus}

In the United Kingdom, EBP has been a preoccupation of several government agencies since the early 1990s. From the early research strategy documents of the Department of Health (DoH, 1991, 1993, 1997, 1998) to the then Secretary of State for Education's speech to the ESRC (Blunkett, 2000) inviting policy to be social-science based, the message has been clear. We need a better research base to inform policy and practice - a position at one level with which it is hard to disagree. However, EBP is not an unproblematic concept. Closer examination of how EBP is currently being perceived and advocated reveals a range of different conceptions, claims and purposes for which it is espoused. Other issues of controversy include the appropriateness of evidence for different purposes, validity and quality, the political issue of who decides what evidence counts, and how evidence is generated and utilized.

This contemporary ${ }^{4}$ surge of interest in EBPP has been traced by several authors (e.g. Coe et al., 2000; Sebba, 1999) to the formation of the Cochrane Collaboration in 1993 and the Centre for Evidence-Based Medicine in Oxford in 1995. A similar development to Cochrane in relation to social and educational policies, the Campbell Collaboration, named after the late Donald Campbell, an experimental methodologist and advocate of the 'experimenting society' (Campbell, 1977), was formally established in Philadelphia, USA in February 2000 (http:// campbell.gse.upenn.edu).

Parallels with education ${ }^{5}$ have been led by Hargreaves (1996) and stimulated a debate on the differences and/or similarities between medicine and teaching, the nature of the practices these professions are engaged in and the relevance of the Cochrane-type evidence to adequately inform professional practice (e.g. Hammersley, 1997, 2001; Elliott, 2001; Hargreaves, 1999; Evans and 


\section{Evaluation 10(4)}

Benefield, 2001). That advances in medicine have resulted primarily from randomized trials has also been queried (e.g. House, 2003; Eraut, 2000). From a different perspective, Eraut (2003) attributes the roots of the EBP movement to research on decision making and, particularly in medicine, to clinical decision analysis (Weinstein and Fineberg, 1980). Other authors (e.g. Sanderson, 2003) locate the trend in the 'what works' agenda promoted by the current Labour government, the emphasis in this policy on effectiveness and measurement of outcomes and belief in the rationality of scientific knowledge to influence policy decisions.

The reasons for this resurgence of interest in EBPP may be located in a number of factors in the current political culture, though these are not necessarily connected. Davies et al. (2000: 1) point to the 'rise in the number of organisations seeking explicitly to advise or influence government in their actions', and 'increasing public and political scepticism towards actions of professionals delivering public services'. In education one can also note the political attention given to several reports in the late 1990s denouncing the quality of educational research (e.g. Tooley and Darby, 1998; Hillage et al., 1998). In the US, House (2003) locates the return of a commitment to the use of randomized experiments, abandoned by the evaluation community years ago as the sole way to conduct evaluation, to an extension of the neo fundamentalism of the Bush administration (House, 2003: 8).

In the plethora of discussion that has ensued over 'evidence-based', distinctions have not always been clear between evidence-based policy (and the forms the evidence can take such as systematic reviews, meta analyses, RCTs, experimental design interventions) and evidence-based practice. This may include the above evidence where relevant but also qualitative evidence derived from case studies, narratives, interview or observational studies that is useful in reaching professional decisions. In their authoritative book on the topic, Davies et al. (2000) note the difference in origin of the two concepts. Evidence-based policy, they say, stems from the 'what matters is what works' agenda; evidence-based practice from a concern to ensure 'that what is being done is worthwhile and that it is being done in the best possible way' (Davies et al., 2000: 1-2). This suggests not only that practitioners may not be doing what is worthwhile (which may be the case in some instances) but also that there is a 'best' way. One implication of such a stance is that if we could only establish what this 'best possible way' is, we could then focus on ensuring how to get that evidence into practice. However there are other ways of conceiving the relationship between evidence and practice, as noted earlier, where applying evidence is not the issue, as this is generated in practice (Elliott, 2001; Eraut, 2003).

In the late 1990s, a number of other terms came to be adopted to reflect the growing awareness of the complexity of 'evidence-based' in informing policy and practice. Tilley (2001: 82-4) draws an important distinction between evidence-led policy, the notion that politics and practices can be derived (emphasis added) from evidence, and evidence-informed - the possibility and desirability of policies and practice being informed by evidence. He casts doubt on the former on several grounds - methodological, practical and ideological not least because such a notion may 'tempt politicians to hide behind evidence 
where real issues of value and political judgement are at stake' (Tilley, 2001: 84). 'Evidence-informed' also came to be the term preferred by several other authors (e.g. Sebba, 1999; Hargreaves, 1999). 'Evidence-informed' acknowledges the intent that policy and practice be informed by evidence, but does not make the direct inferential link that is implicit in 'evidence-led'. In recently suggesting 'evidence-aware', Nutley et al. (2003: 126) indicate even less of a direct connection between evidence and policy or practice. The term practice-based evidence has also come into currency to refer to evidence arising from practice (Eraut, 2003; Simons et al., 2003).

However, despite what seems to have been a broadening of the conception of 'evidence-based', the overriding emphasis in the dominant discourse is that randomized experiments are needed to provide an adequate 'scientific' evidence base to inform policy and practice. See, for example, Fitz-Gibbon's (2003) advocacy for experimental design intervention studies, Sanderson's (2003) critique of the 'instrumental' view of evaluation explicit in government departments' focus on 'what works', Oliver and Conole's (2003) critique of the assumptions underlying the 'dominant model', Tilley's (2001) critique of the RCT as the gold standard for all evaluations, Slavin's (2002) advocacy of RCTs as essential for building confidence in educational research among policy makers and educators and House's (2003) critique of same.

\section{Critique of Dominant Model for Informing Professional Practice}

While relevant for some intervention and treatment studies, there are five particular ways in which this 'gold standard' model fails to provide an adequate basis for professional practice. First, the rhetoric of EBP is frequently linked to a rational model of policy making and a belief in technical-rational models of evidence. However policy is not determined in such a rational way, as Weiss (1977, 1999) among others has indicated, citing reasons such as competing interests, ideologies, institutional constraints, and the shape of policy over time. Moreover, as Schwandt (1997) has reminded us, we need to be aware of one of the reasons why policy makers value technical-rational models of evaluation evidence: "to manage economic and social affairs "rationally" in an apolitical, scientized manner such that social policy is more or less an exercise in social technology' (Schwandt, 1997: 74). Given these observations, it does not make sense, if we wish to influence practice to rely either on technical-rational models of evidence or on a linear link between evidence and policy making, as both ignore the complex social political reality in which professionals have to make moral decisions and judgements. More interactive ways are needed for the engagement with and utilization of a range of evidence, as Patton (1997) espouses. Recently Nutley et al. (2003) have outlined a framework for understanding the evidence-into-practice agenda drawing on different theories of utilization and implementation. The title of their article - 'From Knowing to Doing' - however, still infers a one-way linear process; that the knowledge comes first rather than, for example, being embedded in the doing (as is the case in much of professional practice), and that a consequent task is how to get that knowledge accepted in policy or practice. 


\section{Evaluation 10(4)}

Secondly, the 'gold standard' of EBP represents only one of the three kinds of knowledge Eraut (2000) has identified that are required by professionals in decision making. This is codified knowledge. The others are cultural knowledge and personal knowledge, which are intimately linked to knowledge use defined in terms of what people bring to practical situations that enables them to think and perform (Eraut, 2000: 3-4).

Thirdly, the dominant discourse around this model of EBP fails to incorporate the myriad of factors that professionals take into account in making professional judgements or reflecting in and on action (Schon, 1983). Those who work in complex social, psychological settings, where decision making is a matter of fine professional judgement, know that using evidence from systematic large-scale evaluation studies is only part, and I suspect a small part, of the basis on which we make professional decisions. Our judgements are discerned from experience and utilize wisdom - integrated experience and knowing - as much as specific knowledge or evaluation evidence.

This integrated knowing is very similar to the complex nature of political judgement noted by Isaiah Berlin (1996) which involves 'a capacity for integrating a vast amalgam of constantly changing, multicolored, evanescent, perpetually overlapping data', whether those data are identified by scientific knowledge or by direct perception. Berlin likens the process he is describing to the gift of some novelists who have the capacity to convey a sense of 'direct acquaintance with the texture of life' through a 'highly developed discrimination of what matters from the rest....

Above all, this is an acute sense of what fits with what, what springs from what, what leads to what, how things seem to vary to different observers, what the effect of such experience on them may be; what the result is likely to be in a concrete situation of the interplay of human beings and impersonal forces - geographical or biological or psychological or whatever they may be. (Berlin, 1996: 46)

In the context of medicine, Eraut (2000) makes a similar point in noting that most of the research on diagnosis is focused not on the use of research evidence, but on the expertise of individual clinicians, key features of which he and Du Boulay define as follows:

the importance of case-based experience, the rapid retrieval of information from memory attributable to its superior organisation, the development of standard patterns of reasoning and problem-solving, quick recognition of which approach to use and when, awareness of bias and fallibility; and the ability to track down, evaluate and use evidence from research and case-specific data. (Eraut and Du Boulay, 2000: 99)

In another professional context - assessment in nursing and midwifery education - the concept of 'situational flexibility' (Phillips et al., 2000: 132) is adopted to describe the sensitivity to differences between broadly similar situations and the need to respond in uniquely appropriate ways. This flexibility and ability to cope in complex and unstable situations would not be possible, the authors state, without 'situated understanding' - 'the implicit understanding that enables practitioners to live with and negotiate a way through the competing and 
often contradictory values they encounter regularly as they do "caring", (Phillips et al., 2000: 132).

Situated understanding is built up through past experience, observation of previous cases, and acculturation and negotiation in the work place. Such experience results in a wealth of 'tacit knowledge' (Polanyi, 1958) that informs subsequent professional judgements. The practitioner has to think fast on the ground in making decisions but this is informed by previous judgements and practical theories of what is appropriate in specific contexts. Whether this is called 'natural wisdom' (Berlin, 1996) or 'practical knowledge or wisdom' (Schwandt, 2000), this process of coming to understand and make moral judgements in particular circumstances and contexts is crucial to the enhancement of professional practice.

This view of the decision-making process in professional contexts is far from the linear, rational relationship often assumed between evaluation knowledge and decision making in the EBP movement. Even the model proposed by Nutley and Davies (2000: 324-5) of the 'relationship between evidence and front line practice', which eschews linear stages and sharp boundaries between knowledge production and utilization in favour of knowledge creation through partnerships, does not match the reality of the situated understandings on which professionals act.

Fourthly, the rhetoric of EBP does not address the social and psychological dimensions of change. While policy makers may feel confident with the results of experimental research and large-scale studies (Slavin, 2002), more attention needs to be paid to the context of use and to those individuals or groups who it is hoped will implement policy or utilize evaluation evidence. This is not a straightforward process. There is no simple transfer from evaluation evidence to policy or to practice. Even if experimental evidence suggests that a particular course of action leads to certain outcomes, this does not mean individuals will incorporate such action into their practice. Motivation is crucial. Individual professionals or groups must want to use the results and see the relevance of them to their particular setting. Practice involves people and how we act in relation to the task we have to perform and the students or patients before us. It is not an abstract concept.

It is a sense for what is qualitative rather than quantitative. For what is specific rather than general; it is a species of direct acquaintance, as distinct from a capacity for description or calculation or inference; it is variously called natural wisdom, imaginative understanding, insight, perceptiveness ... as opposed to the markedly different virtues - very great as these are - of theoretical knowledge or learning, erudition, powers of reasoning and generalization ... (Berlin, 1996: 46)

Evidence from an evaluation project on EBP in education, where consortia of schools, higher education institutions and local education authorities collaborated to encourage teachers to engage in and with research, confirms this point. Teachers were more ready to engage with publicly available research results, once they had had experience of doing research themselves in their specific contexts (Elliott, 2000). The timing was important to the perception of relevance. It was engagement in research that created the motivation to look for publicly 


\section{Evaluation 10(4)}

available relevant research, not its mere existence or being informed that it was there and potentially useful.

The evaluation also found that teachers engaged with research evidence generated by their peers, when two conditions were present: first when the evidence retained a connection with common themes and issues in context and secondly, when they had built up trust and confidence in conducting and sharing research experience with their peers. Utilization of knowledge in this context was a social interactive process both in its generation and in its subsequent dissemination to others. The authors use the term practice-based evidence to acknowledge the origin and focus of the research and the concept of 'situated generalization' to indicate how professionals in this context transferred and utilized knowledge. Situated generalization is a three-stage process of understanding, from the personal (the individual teacher investigating a specific issue derived from practice) to the collegial (designed and analysed with colleagues) to the collective (sharing of knowledge across different settings) (Simons et al., 2003: 356-8).

Finally there is the question of values. Individuals may value different kinds of knowledge to inform their action and different evidence may be sought or required to answer different questions. In speaking of EBP, we need to be clear that RCT evidence, even if available, ${ }^{6}$ is only one kind of evidence that has limited applicability to how professionals change their practice. Practice settings and the complexity of professional judgements they entail call for a range of evaluation evidence and an awareness that whether evidence, of whatever kind, is utilized is a matter of values, personal preference, professional judgement and 'practical knowledge or wisdom'.

\section{Justification of Lived Experience as a Source of Evidence}

I now turn to a different kind of evidence - narratives of personal experience to show how and why this has more potential for improving professional practice. I choose to do this through a focus on the clinical narrative for two reasons. First, it raises a moral question about the nature of evidence and the role we have as professionals to respect the autonomy of our patients, clients and students. Secondly it reconnects persuasively with those forms of evaluation evidence briefly outlined in the second section that have given us greater purchase in evaluation on understanding how educational and social innovations bring about change in practice. At the bottom line, this is an argument for the revaluing of 'lived experience' as a source of evidence for enhancing professional practice.

In education, writers such as Van Manen (1990), Clandinin and Connelly (1990), Bochner (2001), Aoki (1993) and Grumet (1988) among others have argued the phenomenological case for documenting lived experience. A focus on the illness narrative, arguably, raises the moral issue most sharply as individuals encounter quite vulnerable, intimate and uncertain situations.

\section{Valuing Lived Experience}

For justification of 'lived experience' which forms the basis for many of the stories we tell in evaluation, I draw on a paper by a philosopher titled 'Lived 


\section{Simons: Utilizing Evaluation Evidence to Enhance Professional Practice}

Experience and Values in Health Care' (Toombs, 2000). Kay Toombs, the author, is a most appropriate person to present this justification as she has 'lived the experience' she establishes the case for in this paper. Having been diagnosed with multiple sclerosis many years ago, she has been intimately involved in healthcare from the perspective of the patient.

Toombs' (2000) justification for researching 'lived experience' is embedded in phenomenology, in the interaction of two levels of analysis, one concerned with the structuring of experiencing, the other with the kinds of experiences people go through, the 'thick description' (personal narrative) of the experience. There are four particular features of Toombs' analysis that are pertinent to the case for personal narrative as evidence.

The first is what happens when the 'taken for grantedness' of normal bodily experience is disrupted. In normal circumstances, she comments, 'we live our bodies unreflectively', the body remains unnoticed, the background rather than the foreground of attention. In physical disorder, this 'taken for grantedness' is up-ended.

The body appears in some ways separated from the self, having a will of its own, disrupting plans and projects. At the same time there is a symbiotic relation between self and body. Whatever happens to IT necessarily also happens to ME. Consequently, the loss of bodily taken-for-grantedness is felt as an acute threat to the self (Toombs, 2000: 2).

A second key characteristic of lived experience, Toombs notes, is the dynamic relation between body and environment: 'we are not just bodily beings but beings-in-the-world, always situated within and interacting with our environment' (Toombs, 2000: 2). In this analysis, illness is not just a physical disorder but a disruption in the interactive relationship between body and environment. Objects take on a different significance becoming a problem to the body. For someone in a wheel chair or who has angina, for example, stairs take on a different dimension than for someone who is not or who has no heart problem.

Third, Toombs draws our attention to the values inherent in embodiment. She cites an example here of the value of upright posture in our culture and says that it should not be underestimated as a component of the illness experience. 'To be able to "stand on one's own two feet" is of more than figurative significance. Verticality is directly related to autonomy' (Toombs, 2000: 3). The example she cites stems from her own experience of travelling and how she is treated by airport officials who ask her husband if SHE can walk and what SHE needs, as though she does not have a voice and presence. The point she is making here is critical when considering how to interact effectively in the clinical encounter and devise appropriate therapies and policies to support an individual's independence. As an aside, she notes (and this is in brackets in her paper) that 'though the loss of upright posture, in and of itself, is intrinsically diminishing, cultural and social values that celebrate a certain ideal of health and fitness add to the devaluation of those with physical disabilities' (Toombs, 2000: 3).

The fourth point is the distinction Toombs draws between a clinical narrative and a medical history, which resonates with the characterization of professional practice discussed earlier. Taking a phenomenological view - in this case, of 


\section{Evaluation 10(4)}

illness - shifts the focus to the kinds of experiences patients go through and the meanings of those experiences which are affected by one's life history and context, cultural and ethnic background, value system, prior experience and so on. The patient's personal story is as important as any analysis of typical characteristics. Here is how Toombs describes the clinical personal narrative distinguishing it from a medical history:

The clinical narrative is the story of illness from the patient's point of view. Such narratives not only disclose what a particular illness means for a particular person, but also reveal what it is like to suffer from a particular disease ... Clinical narratives do not operate at the level of objective pathology. They are not primarily concerned with such matters as elevated blood counts, demonstrable lesions, or abnormal EKG's. They detail the patient's experience of lived bodily disruption - of the disorder of body, self and world that illness represents. In the practical arena of health care, clinical decisions are necessarily imbued with value. As Pellegrino has noted: the end of the clinical encounter is not just what can be done for this particular patient, but what ought to be done. Determining what ought to be done requires one to situate the illness experience in the context of the patient's life narrative. (Toombs, 2000: 4)

In this description of the clinical narrative we can see the concept of professional practice as a moral activity referred to earlier. The personal narrative is a significant source of evidence in making decisions about how to act. In making this case I have focused on the clinical narrative. However the case it presents is equally applicable to other contexts and professions where educational, social and cultural values are embedded in the taken-for-granted experience and affect how those who are different perceive and are received by those around them. Take the silent pupil in the classroom, for instance, who comes up against the vocal norm. Not finding her experience listened to or valued, she may become a social isolate as well as lag behind in her work. Or the elderly person who wishes to retain her independence against the pressure to locate her in a sheltered home. Or the teenager from a different culture who does not understand the peer subculture and feels rejected when not included.

Unique personal narratives are important not only to help us understand individuals' experience but also to the professional and moral decision that needs to be made about their achievement, care and social life. For further discussion of the use of personal narrative and story in evaluation see Abma (2001a) and in clinical judgement, see Greenhalgh (1999).

\section{Telling the Story}

That is the case for personal narrative. How it is constructed is equally important, for this has political and ethical consequences for the person whose experience it is. Eliciting the 'lived experience' is the evaluator's task. In reporting, it is crucial to maintain the integrity and validity of that experience. There are many examples of how to do this in the evaluation literature - vignettes, cameos, dialogues, case studies and profiles - to name a few. In one way or another, these forms of representation all tell a story. The critical question is who tells - the person whose experience it is; the evaluator, drawing on interview, observational data and 'significant others'; the evaluator in dialogue with the person whose 


\section{Simons: Utilizing Evaluation Evidence to Enhance Professional Practice}

experience is being reported? Methodological and political questions are associated with each of these choices, which there is no space to explore here. Suffice to say that what we gain from the thick description of stories and personal narratives is a rich source of experiential evidence for informing professional decisions. Carefully researched, written and validated, they are also an important source of evaluation evidence for how programmes are enacted and valued. Kushner (2000) has made a compelling case for inverting the way we traditionally evaluate programmes by suggesting that the main frame for understanding social programmes should be a focus on individuals' experience rather than the programme itself. Programmes only live through those who implement them. Participants' stories therefore have a persuasive role to play in understanding the value of the programme.

Story of course has a long tradition of communicating directly about the essential values of human kind, as Ben Okri (1997) has eloquently argued in A Way of Being Free. They have an ineffable power that steals up on you and enables you to understand and see differently. 'Stories are living things ... and their real life begins when they start to live in you. Then they never stop living, or growing, or mutating, or feeding the groundswell of imagination, sensibility and character' (1997: 44). Though Okri may have been speaking about the fables and stories of history, the parallel to storytelling in evaluation and research is clear. Insights we gain from people's stories of their experience have the power to change how we see their world.

Telling the story is one step. It is the dialogue that ensues from that story and the further questions that get asked that generate further interpretation and understanding. In democratic evaluation studies (e.g. Simons, 1987; MacDonald et al., 1987), dialogue and negotiation are an essential part of the process not only of coming to understand what people think and value but also in apprehending the policy context of use. Through dialogue, it becomes apparent how and when evaluation data can best inform decision making. This is a point House and Howe (1999) have also argued for in drawing attention to the need to engage policy makers much earlier in deliberative discussion than we frequently do. The importance of dialogue as a methodology and political process in programme and project evaluation has been further elaborated in a special issue of the journal Evaluation (2001, Vol. 7, No. 2; see Abma, 2001b).

There remains, according to one reviewer of this article, the difficulty of connecting the 'experiential/personal' with the 'scientific/collective' in order to provide a 'safe' basis for decisions involving human and financial resources. From a practitioner perspective, there is a sense in which this is not the issue. Individual practitioners will decide how best to take account of the range of available, relevant evidence - personal, 'practice-based' or 'scientific' - to enhance their professional practice. From a policy level, seeking evaluation evidence to advocate such practice (and possible resource allocation), it may be useful to examine the methodologies that are developing to analyse large-scale, qualitative data sets. For two such examples see the work of Schostak (2002) using computer analysis of large-scale qualitative interviewing for collective knowledge building and Elliott (2000) exploring large-scale data sets (qualitative and quantitative) 


\section{Evaluation 10(4)}

in collaborative action research. Both these approaches are extensive in scope yet retain the essential connectedness with the practice settings in which the evidence is generated and hence can offer a more comprehensive understanding of the issue or system than a quantitative approach. Such qualitative evidence is also less vulnerable to manipulation for political agendas.

\section{Conclusion}

In the end as Davies (1999: 117) has pointed out, educators [in all professions] [author's addition in brackets] need access to the best available evidence and to critically appraise it in order to determine its relevance or lack of relevance to their schools, students and educational needs. We may differ on what best evidence is and that is a value judgement and preference. But as Davies says:

Evidence based education, like evidence based health care, is not a panacea, not a quick fix, cookbook practice or the provider of ready-made solutions to the demands of modern education. It is a set of principles and practices which can alter the way people think about education, the way they go about educational policy and practice, and the basis upon which they make professional judgements and deploy their expertise. (Davies, 1999: 118)

With this definition we have in a sense come full circle. In viewing EBP as a set of principles and practices, Davies both rejects the linear adoption of evidence in a rational policy-making model and brings us back to the use of evaluation evidence in the broader context of informing decision making, with which I started. This is a multifaceted and complex political enterprise, which involves negotiating evidence and research knowledge from different sources and methodologies in diverse organizations and contexts. What has been argued for here, in a context of the contemporary EBP debate, is a revaluing of the knowledge gained from documentation of 'lived experience' as a important source of evidence, both as a counter to the dominant model in currency and as a form of data that is more likely to inform professional practice.

\section{Notes}

I would like to thank Kay Toombs for her agreement to include the essence of her argument on the phenomenological case for the personal narrative and three anonymous reviewers for their most helpful comments.

1. This is a revised version of a paper presented at the European Evaluation Society 5th Biennial Conference 'Three Movements in Contemporary Evaluation: Learning, Theory and Evidence', Seville, Spain, 10-12 October 2002.

2. The term evidence-based practice (EBP) is not always used consistently in the literature. In this article, it refers primarily to evidence that affects professional practice and indirectly to policy initiatives.

3. One of the reviewers of this article thought it was important to distinguish evaluation from research in order to clarify the distinctive contribution of 'evaluation evidence'. One way of distinguishing is as follows. Traditionally research seeks to answer questions 


\section{Simons: Utilizing Evaluation Evidence to Enhance Professional Practice}

that the researcher is asking and adds to the cumulative sum of knowledge of a particular topic for its own sake, whereas evaluation seeks to answer questions others are asking to inform their decision making, and is more concerned with the utilization of knowledge in particular socio-political contexts. Evaluation is also inherently political producing evidence about the value or merit of a programme or policy that can be used in the allocation of resources and opportunities in society. Whose interests and values are served in an evaluation is therefore a critical issue. In the current political climate, it is possible to argue that research has a strong evaluative component. Any difference it is possible to posit between research and evaluation is lessened because research is perceived as instrumental to policy - with a strong steer or prescription from government as to what questions get asked and answered for what purpose. Research-based evidence can also be used for evaluation purposes. For further discussion on this point see MacDonald (1976), Weiss $(1977,1999)$ and Torrance (2003).

4. Several authors have pointed out (e.g. Hargreaves, 1997; Coe et al., 2000) that 'evidence-based' medicine has a history tracing back to the 19th century. However it is the current interest in 'evidence-based' that is the focus here.

5. In education, the Department for Education and Employment has taken a central role in funding The Evidence for Policy and Practice Information and Co-ordinating Centre (EPPI-Centre) based at the Social Science Research Unit, University of London, Institute of Education. The Centre has been set up to conduct and support systematic reviewing of the educational research literature 'and assessing them in an explicit and standard way so as to produce accessible syntheses of research findings' (British Educational Research Association, 2000).

The Curriculum, Evaluation and Management Centre at Durham University has also been prominent in the promotion of evidence-based education. The Centre believes there is a need to go beyond systematic review of existing research evidence (as in education there are many areas where the research does not exist) to conduct multiple RCTs of interventions in real-life settings (Coe et al., 2000).

6. In a recent study (Eraut, 2003), the proportion of medical decisions for which 'gold standard' evidence is available was cited by medical consultants to be no higher than 20 percent, though all agreed the figure was rising.

\section{References}

Abma, T. (1999) 'Introduction: Narrative Perspectives on Program Evaluation', in T. Abma (ed.) Telling Tales: On Evaluation and Narrative, Advances in Program Evaluation 6, pp. 1-27. Stamford, CT: JAI Press.

Abma, T. (2001a) 'Evaluating Palliative Care: Facilitating Reflexive Dialogues about an Ambiguous Concept', Medicine, Health Care and Philosophy 4(3): 261-76.

Abma, T. (2001b) 'Opening Thoughts', Evaluation 7(2): 155-63.

Aoki, T. (1993) 'Legitimizing Lived Curriculum: Towards a Curricular Landscape of Multiplicity', Journal of Curriculum and Supervision 8(3): 255-8.

Berlin, I. (1996) The Sense of Reality. London: Chatto and Windus.

Blunkett, D. (2000) 'Influence or Irrelevance: Can Social Science Improve Government?', Secretary of State's ESRC Lecture, London, UK: 2 February.

Bochner, A. (2001) 'Narrative's Virtues', Qualitative Inquiry 7(2): 131-57.

British Educational Research Association (2000) 'The Evidence for Policy and Practice Information and Co-ordinating Centre (EPPI-Centre)', Research Intelligence 73: 25. Available at: http://www.bera.ac.uk/ri/no73/ri73eppicentre.html (site visited: 25 September 2004). 


\section{Evaluation 10(4)}

Campbell, D. T. (1977) 'Keeping the Data Honest in the Experimenting Society', in H. W. Melton and D. H. G. Watson (eds) Interdisciplinary Dimensions of Accounting for Social Goals and Social Organizations, A Conference of the Department of Accountancy, pp. 37-76. Columbus, OH: University of Illinois, Urbana-Champaign, Grid.

Chelimsky, E. (1997) 'Thoughts for New Evaluation Society', Evaluation 3(1): 97-118.

Clandinin, J. and M. Connelly (1990) 'Personal Experience Methods', in N. K. Denzin and Y. S. Lincoln (eds) Handbook of Qualitative Research, pp. 413-27. London: Sage.

Coe, R., C. Fitz-Gibbon and P. Tymms (2000) 'Promoting Evidence-based Education: The Role of Practitioners', Roundtable presentation to the British Educational Research Association's Annual Conference, Cardiff, Wales: 7-9 September.

Cronbach, L. J. (1963) 'Course Improvement through Evaluation', Teachers College Record 64(8): 672-83.

Cronbach, L. J., S. R. Ambron, S. M. Dornbusch, R. D. Hess, R. C. Hornik, D. C. Phillips, D. F. Walker and S. S. Weiner (1980) Toward Reform of Program Evaluation: Aims, Methods and Instructional Arrangements. San Francisco, CA: Jossey-Bass.

Davies, H. T. O., S. M. Nutley and P. C. Smith, eds (2000) What Works? Evidence-Based Policy and Practice in Public Services. Bristol: The Policy Press.

Davies, P. (1999) 'What is Evidence-Based Education?', British Journal of Educational Studies 47(2): 108-21.

Department of Health (1991) Research for Health: a Research and Development Strategy for the NHS. London: Department of Health, Research and Development Division.

Department of Health (1993) Research for Health. London: Department of Health.

Department of Health (1997) Research and Development: Towards an Evidence-Based Health Service. London: Department of Health, Research and Development Division.

Department of Health (1998) Research and Development: Towards an Evidence-Base for Health. Services, Public Health and Social Care: Information Pack. London: Department of Health, National Health Service Executive.

Dowell, J., G. Huby and C. Smith, eds (1995) Scottish Consensus Statement on Qualitative Research in Primary Health Care. Dundee: Tayside Centre for General Practice, University of Dundee.

Eisner, E. W. (1985) The Art of Educational Evaluation: A Personal View. London: Falmer.

Elliott, J. (1990) 'Teachers as Researchers: Implications for Supervision and for Teacher Education', Teaching and Teacher Education 6(1): 1-26.

Elliott, J. (2000) 'How Do Teachers Define What Counts as "Credible Evidence"? Some Reflections Based on Interviews with Teachers Involved in the Norwich Area Research Consortium', Paper presented at the British Educational Research Association's Annual Conference, Cardiff, Wales: 7-9 September.

Elliott, J. (2001) 'Making Evidence-Based Practice Educational', British Educational Research Journal 27(5): 555-74.

Eraut, M. (2000) 'The Dangers of Managing with an Inadequate View of Knowledge', Paper presented to the Third International Conference of Socio-Cultural Psychology, Brazil: July.

Eraut, M. (2003) 'Practice-Based Evidence', in G. Thomas and R. Pring (eds) EvidenceBased Policy and Practice. Milton Keynes: Open University Press.

Eraut, M. and B. Du Boulay (2000) 'Developing the Attributes of Medical Professional Judgement and Competence', Report to the UK Department of Health. London: Department of Health.

Evans, J. and P. Benefield (2001) 'Systematic Reviews of Educational Research: Does the Medical Model Fit?', British Educational Research Journal 27(5): 527-41. 


\section{Simons: Utilizing Evaluation Evidence to Enhance Professional Practice}

Fitz-Gibbon, C. T. (2003) 'Milestones En Route to Evidence-based Policies', Research Papers in Education: Policy and Practice 18(4): 313-29.

Goldstein, H. (1991) 'Qualitative Research and Social Work: Partners in Discovery', Journal of Sociology and Social Welfare 18(4): 101-18.

Greene, J. C. (1994) 'Qualitative Program Evaluation: Practice and Promise', in N. K. Denzin and Y. S. Lincoln (eds) Handbook of Qualitative Research, pp. 530-54. London: Sage.

Greenhalgh, T. (1999) 'Narrative Based Medicine in an Evidence Based World', British Medical Journal 318(7179): 323-5.

Greenhalgh, T. and J. G. Worrall (1997) 'From EBM to CSM: the Evolution of Context Sensitive Medicine', Journal of Evaluation in Clinical Practice 3(2): 105-8.

Grumet, M. (1988) Bitter Milk: Women and Teaching. Amherst: University of Massachusetts Press.

Guba, E. G. and Y. S. Lincoln (1989) Fourth Generation Evaluation. London: Sage.

Hammersley, M. (1997) 'Educational Research and Teaching: a Response to David Hargreaves' TTA Lecture', British Educational Research Journal 23(2): 141-61.

Hammersley, M. (2001) 'On "Systematic" Reviews of Research Literatures: a "Narrative" Response to Evans and Benefield', British Educational Research Journal 27(5): 543-54.

Hargreaves, D. H. (1996) Teaching as a Research-based Profession: Possibilities and Prospects (Teacher Training Agency Annual Lecture 1996). London: TTA.

Hargreaves, D. H. (1997) 'In Defence of Research for Evidence-based Teaching: a Rejoinder to Martyn Hammersley', British Educational Research Journal 23(4): 405-19.

Hargreaves, D. H. (1999) 'Revitalising Educational Research: Lessons from the Past and Proposals for the Future', Cambridge Journal of Education 29(3): 239-50.

Hillage, J., R. Pearson, A. Anderson and P. Tamkin (1998) Excellence in Research on Schools. London: Department for Education and Employment.

House, E. R. (1980) Evaluating With Validity. Beverly Hills, CA: Sage.

House, E. R. (2003) 'Bush's Neo-Fundamentalism and the New Politics of Evaluation', Studies in Educational Policy and Educational Philosophy 2. Uppsala, Sweden [www. upc.artisan.se].

House, E. R. and K. R. Howe (1999) Values in Evaluation and Social Research. London: Sage.

Humphries, B. (2003) 'What Else Counts as Evidence in Evidence-based Social Work?', Social Work Education 22(1): 81-91.

Kushner, S. (2000) Personalizing Evaluation. London: Sage.

MacDonald, B. (1976) 'Evaluation and the Control of Education', in D. Tawney (ed.) Curriculum Evaluation Today: Trends and Implications. London: Macmillan.

MacDonald, B. and R. Walker (1975) 'Case Study and the Social Philosophy of Educational Research', Cambridge Journal of Education 5(1): 2-11.

MacDonald, B., M. Argent, J. Elliott, N. May, P. Miller, J. Naylor and N. Norris (1987) Police Probationer Training: The Final Report of the Stage II Review. London: Her Majesty's Stationery Office.

Norris, N. (1991) Understanding Evaluation. London: Kogan Page.

Nutley, S. M. and H. T. O. Davies (2000) 'Making a Reality of Evidence-based Practice', in H. T. O. Davies, S. M. Nutley and P. C. Smith (eds) What Works? Evidence-Based Policy and Practice in Public Services, pp. 317-50. Bristol: The Policy Press.

Nutley, S., I. Walter and H. T. O. Davies (2003) 'From Knowing to Doing: a Framework for Understanding the Evidence-into-practice Agenda', Evaluation 9(2): 125-48.

Oakley, A. (1998) 'Experimentation and Social Interventions: a Forgotten but Important History', British Medical Journal 317(7617): 1239-42. 


\section{Evaluation 10(4)}

Okri, B. (1997) A Way of Being Free. London: Phoenix.

Oliver, M. and G. C. Conole (2003) 'Evidence-based Practice and E-learning in Higher

Education: Can We and Should We?', Research Papers in Education: Policy and Practice 18(4): 385-97.

Patton, M. Q. (1997) Utilization-Focused Evaluation, 3rd edn. London: Sage.

Phillips, T., J. Schostak and J. Tyler (2000) Practice and Assessment: an Evaluation of the Assessment of Practice at Diploma, Degree and Postgraduate Level in Pre and Post Registration Nursing and Midwifery Education. Final Report. Norwich: CARE School of Education and Professional Development, University of East Anglia; and London: English National Board for Nursing, Midwifery and Health Visiting.

Polanyi, M. (1958) Personal Knowledge: Towards a Post Critical Philosophy. New York: Harper and Row; and London: Routledge and Kegan Paul.

Ryan, K. E. and L. DeStefano, eds (2000) Evaluation as a Democratic Process: Promoting Inclusion, Dialogue and Deliberation. New Directions for Evaluation 85. San Francisco, CA: Jossey-Bass.

Sackett, D. L., W. M. C. Rosenberg, J. A. M. Gray, R. B. Haynes and W. S. Richardson (1996) 'Evidence-based Medicine: What It Is and What It Isn't', British Medical Journal 312(7023): 71-2.

Sanderson, I. (2003) 'Is it "What Works" that Matters? Evaluation and Evidence-based Policy Making', Research Papers in Education: Policy and Practice 18(4): 331-45.

Schon, D. (1983) The Reflective Practitioner: How Professionals Think in Action. London: Temple Smith.

Schostak, J. (2002) Understanding, Designing and Conducting Qualitative Research in Education. Framing the Project. Milton Keynes: Open University Press.

Schwandt, T. A. (1997) 'Evaluation as Practical Hermeneutics', Evaluation 3(1): 69-83.

Schwandt, T. A. (2000) 'Further Diagnostic Thoughts on What Ails Evaluation Practice', American Journal of Evaluation 21(2): 225-9.

Sebba, J. (1999) 'Developing Evidence-informed Policy and Practice in Education', Paper presented to the British Educational Research Association Conference, Brighton, UK: 2-5 September.

Shaw, I. (1999) Qualitative Evaluation. London: Sage.

Shaw, I. and N. Gould (2001) Qualitative Research in Social Work: Context and Method. London: Sage.

Simons, H. (1987) Getting to Know Schools in a Democracy: the Politics and Process of Evaluation. Lewes: Falmer Press.

Simons, H. (1996) 'The Paradox of Case Study', Cambridge Journal of Education 26(2): 225-40.

Simons, H., S. Kushner, K. Jones and D. James (2003) 'From Evidence-based Practice to Practice-based Evidence: the Idea of Situated Generalisation', Research Papers in Education: Policy and Practice 18(4): 347-64.

Slavin, R. E. (2002) 'Evidence-based Education Policies: Transforming Educational Practice and Research', Educational Researcher 31(7): 15-21.

Stake, R. E. (1967) 'The Countenance of Educational Evaluation', Teachers College Record 68(7): 523-40.

Stake, R. E. (1995) The Art of Case Study Research. London: Sage.

Stenhouse, L. (1975) An Introduction to Curriculum Research and Development. London: Heinemann.

Stufflebeam, D. L., W. J. Foley, W. J. Gephart, E. G. Guba, R. I. Hammond, H. O. Merriman and M. M. Provus (1971) Educational Evaluation and Decision Making. Itasca, IL: F.E. Peacock. 


\section{Simons: Utilizing Evaluation Evidence to Enhance Professional Practice}

Tilley, N. (2001) 'Evaluation and Evidence-led Crime Reduction Policy and Practice', in R. Matthews and J. Pitts (eds) Community Safety, pp. 81-97. London: Routledge.

Tooley, J. and D. Darby (1998) Educational Research: a Critique. A Survey of Educational Research. London: Office Standards in Education.

Toombs, K. (2000) 'Lived Experience and Values in Health Care', Paper presented to conference on Values in Health Policy, Ontario, Canada: May.

Torrance, H. (2003) 'When Is an "Evaluation" Not an Evaluation? When It Is Sponsored By the QCA?: A Response to Lindsay and Lewis', British Educational Research Journal 29(2): 169-73.

Van Manen, M. (1990) Researching Lived Experience: Human Science for an Action Sensitive Pedagogy. New York: SUNY Press.

Weinstein, M. C. and H. V. Fineberg (1980) Clinical Decision Analysis. Philadelphia, PA: WB Saunders.

Weiss, C. H. (1975) 'Evaluation Research in the Political Context', in E. L. Struening and M. Guttentag (eds) Handbook for Evaluation Research 1: 13-26. Beverly Hills, CA: Sage.

Weiss, C. H., ed. (1977) Using Social Research in Public Policy Making. Lexington, MA: Lexington Books.

Weiss, C. H. (1999) 'The Interface between Evaluation and Public Policy', Evaluation 5(4): 468-87.

HELEN SIMONS is Professor of Education and Evaluation at the University of Southampton, UK, specializing in programme, policy and institutional evaluation.

She has published on case study, institutional self-evaluation, democratic evaluation, qualitative methodology and the ethics of evaluation. Her evaluation practice focuses on educational programmes in the professions of education, health and social care. Please address correspondence to School of Education, University of Southampton, Southampton S0I7 IBJ, UK.

[email: h.simons@soton.ac.uk] 